\title{
Ô Estética, historicismo y praxis política: Gramsci y el arte
}

\section{Salvador Orlando Alfaro}

Universidad de Regina, Canadá

Resumen: Las reflexiones críticas en el campo de la estética, elaboradas por Antonio Gramsci en el curso de su producción teórica, constituyen una fuente importante para el estudio e interpretación del arte desde una posición militante del materialismo histórico. El problema central de la teoría estética de Gramsci está vinculado a su noción de historicidad y de la autonomía relativa del arte. El arte a pesar de su determinación por la cultura, la sociedad y la historia, se caracteriza por una "historicidad concreta". El grado de complejidad del enfoque de Gramsci, los problemas de la temporalidad del arte, la relación entre la crítica estética y la crítica política, y el arte popular y la transformación social son las temáticas abordadas en la presente discusión.

Abstract: The critical reflections made by Antonio Gramsci on the field of aesthetics consitute an important source for the study and interpretation of Art from a militant position of historical materialism. The central problem of Gramsci's aesthetic theory is linked to his notion of historicity and of the relative autonomy of art. In spite of its determination by culture, society and history, art is characterized by a "concrete historicity". The degree of complexity of Gramsci's approach, the relationship between aesthetic and political critique, and popular art and social transformation are the main themes with which the following discussion deals.

Palabras claves: Estética, Antonio Gramsci, sociología del art, marxismo, culture, cultura popular.

Keywords: Aesthetics, Antonio Gramsci, Sociology of art, Popular culture, Marxism, Culture. 


\section{Introducción}

Las notas de Gramsci sobre el tema de las artes y la crítica literaria han sido comentadas desde diversos puntos en vista de su carácter creativo y enriquecedor, especialmente dentro de la tradición marxista y desde hace algún tiempo en los estudios culturales. Sus reflexiones han influenciado a una gran cantidad de críticos y académicos. Sin embargo, como con la mayoría de sus escritos, su naturaleza fragmentaria, inacabada y polémica ha generado una enorme controversia y debates en torno a su "correcta" interpretación. Existen algunos que interpretan sus percepciones como indicador de una metodología general para una teoría marxista del arte y la estética (Morton, 2003), y existen otros que niegan este punto de vista al insistir en la dependencia obvia que muestra en relación a la filosofía estética de Benedetto Croce (Anderson, 1976). Sin embargo, lo que obviamente existe en el revolucionario italiano es que su interés en los problemas estéticos y en la crítica estética no reside en presentar un esquema teórico de la teoría de la estética, sino en tener claro para sí mismo -y para otros militantes revolucionarios- la naturaleza y función de la crítica en la transformación socialista (Gramsci, 2008).

Desde esta perspectiva, las similitudes entre Gramsci y los enfoques desarrollados por la llamada Escuela de Frankfurt (Jay, 1973) resultan Llamativos. En la soledad de sus reflexiones, Gramsci llega a una concepción no determinista de la relación entre estructura y superestructura. Gramsci se resiste a concebir el arte como una reflexión pasiva de los intereses de clase. El arte posee una autonomía relativa y contiene un valor a través de los tiempos. Como los teóricos de la Escuela de Frankfurt (pioneros en el análisis sociológico de la estética), Gramsci visualiza el arte como componente de una cultura, una forma por medio de la cual la conciencia de una época histórica puede expresarse. En tal sentido, habla de la necesidad de crear un "orden". "La ausencia de un orden artístico (...) está relacionado con la ausencia de un orden intelectual y moral; es decir, con la ausencia de un desarrollo histórico orgánico" (Gramsci, 2007, p. 2,242). Sin embargo, en contraste con los enfoques de la Escuela de Frankfurt, y a pesar que mantiene los principios de la historicidad y de la relativa autonomía del arte y su independencia de la esfera política, Gramsci habla de la necesidad de "popularizar el arte". Asimismo, intenta resolver la antinomia de la historicidad del arte y su inmortalidad, como Marx (1972) lo hace, de una manera muy cercana a los enfoques de la Escuela de Frankfurt. De igual manera, intenta 
también resolver la antinomia, de tal forma de asegurar la inmortalidad del arte sin comprometer la integridad de su teoría del "historicismo absoluto". En el mismo sentido, su teoría también se contrapone a la concepción idealista de Croce (2004) en la medida que trata de fundamentar la historicidad del arte, ya que para Croce no debe existir una preocupación por dilucidar el propósito del arte y su relación con la historia. Para Gramsci, entonces, la historicidad del arte constituye un componente imperativo del análisis del fenómeno artístico, considerado éste como un problema delicado para la filosofía de la praxis.

El presente ensayo tiene como objetivo discutir como teóricamente Gramsci intenta resolver los problemas complejos de la estética marxista al introducir en su análisis la noción de dialéctica. Solamente aceptando una perspectiva dialéctica los peligros del formalismo, psicologismo, sociologismo o cualquier otra forma de dogmatismo y determinismo podrían evitarse. Debido a que la praxis humana es dialéctica, el arte necesariamente refleja sus contradicciones, al mismo tiempo que refleja lo que es permanente en el proceso histórico. El arte es -para Gramsci- un trabajo inacabado. El arte, en términos generales, siempre se encuentra delante de su tiempo: buscando imaginariamente a la sociedad ideal del futuro. Gramsci examina la relación entre la historia y el arte, entre forma y contenido, y la crítica estética y política como componentes fundamentales de una visión del mundo que intenta transformar la sociedad existente. Estas temáticas son el objetivo de nuestros comentarios.

\section{La dimensión temporal del arte en el historicismo de Gramsci}

Gramsci enfoca el problema del arte formulando dos interrogantes sociológicas: ¿Qué es lo bello en las obras de arte? y ¿Por qué el arte? Para responder a estas interrogantes es necesario establecer por qué un cierto tipo de arte es disfrutado solamente por los que lo reciben, y por qué los poetas escriben o los pintores pintan. Croce (uno de los referentes intelectuales de mayor influencia en Gramsci) responde a estas interrogantes afirmando que las obras de arte son producidas para ser recordadas. Los artistas, Gramsci afirma por el contrario, no existen en el vacío, viven en una sociedad históricamente determinada. Sus imágenes no son simplemente "expresadas" de modo que el instante de su creación pueda ser re-creado. El artista es quien objetiviza e historiza sus fantasmas. Mientras más histórico es un artista, más objetivas y eternas son sus creaciones (Gramsci, 2007, p. 1,686). 
El valor del arte es extrínseco a éste, el mismo se sustenta en la relación del artista con su sociedad, su tiempo y las condiciones históricas generales. El arte no es un producto de sí mismo, sino de la historia.
Cuando un arte nuevo se desarrolla, de hecho, son creadas nuevas relaciones sociales, y con ellas una nueva cultura, nuevos sentimientos e imágenes. Gramsci cita un importante texto de Croce:

La poesía no engendra poesía; partenogénesis no se lleva a cabo; lo que se necesita es la intervención del elemento masculino [sic.], es decir, lo que es real, pasional, práctico y moral (...) Una vez el hombre es renovado y el espíritu refrescado, una vida nueva afectiva es creada, de lo que emergerá una nueva poesía. (Gramsci, 2007, p. 732)

Gramsci acepta la afirmación de Croce pero le da una interpretación marxista.

La literatura no engendra literatura, etc... que las ideologías no crean ideologías, las superestructuras no engendran superestructuras (...) ellas son desarrolladas, no a través de partogénesis, sino por la intervención del "elemento masculino" [sic.], el cual es la historia, la actividad revolucionaria que crea un "hombre nuevo", es decir nuevas relaciones sociales. (Gramsci, 2007, p. 732)

El arte es praxis, y como tal depende de la praxis histórica. Dicha dependencia, sin embargo, no es pasiva, estática, inequívoca, sino dialéctica y activa. El arte en sí mismo es un proceso contradictorio que tiende hacia una homogenización y expresión de significados (Scalia, 1968, pp. 338-339). No es suficiente demostrar la historicidad del arte, es necesario saber qué arte expresa mejor la misma fase socio-histórica. La manera en que Gramsci plantea la relación entre el arte y la historia es similar a la de Marx y Engels. Éste último fue un admirador de Balzac a pesar de sus creencias ideológicas burguesas, porque fue capaz de representar a los nuevos hombres y mujeres de la sociedad del futuro y predecir la caída de la aristocracia de su tiempo. El arte de Balzac es objetivo porque se arraiga a una realidad concreta (Arvon, 1973, p. 12). Lo mismo puede decirse -de acuerdo con Gramsci- de la poesía, piezas teatrales y cuentos cortos de Pirandello. Su producción es una contribución a la crítica de la vida social e intelectual de una 
fase de la historia italiana. Como lo comenta Stipcevic, Gramsci está interesado en diferenciar el mundo ideológico del artista y de la "belleza como tal". La belleza, sin embargo, no es un elemento estático en una concepción dinámica del proceso histórico, ésta cambia con la historia y cambia, incluso, en el curso de su permanencia a través de la historia. Las obras de arte adquieren nuevos significados en el proceso de su re-creación. Así, al trascender las intenciones de sus creadores y los intereses de sus contemporáneos, estos productos se transforman a sí mismos. Esta "potencialidad del arte" -Stipcevic continúa- explica su carácter y poder misteriosos al mover y atraer generaciones y generaciones de seres humanos (Stipcevic, 1968, p. 50). Las razones de la permanencia del arte en la historia no se explican para Gramsci por razones psicológicas, sino por factores sociológicos e históricos.

Sin embargo, Gramsci no sustenta su argumentación enfatizando en el problema de la esteticidad del arte y su permanencia a través del tiempo, sino que trata el problema de la estética en conjunción con el problema de la hegemonía y de la creación de una cultura nueva. Gramsci, tomando como punto de reflexión la experiencia soviética, se pregunta: ¿Cómo es posible que de una nueva civilización socialista ya nacida, nuevas formas artísticas y literarias no hayan todavía brotado? El arte es un aspecto de la cultura. No pueden existir movimientos o luchas por un arte nuevo separados de una lucha por una cultura nueva.

Luchar por un arte nuevo significaría luchar para crear nuevos artistas individuales, lo cual es absurdo, los artistas no pueden ser creados artificialmente. Uno tiene que hablar de luchar por una cultura nueva, es decir, una nueva vida moral, intimamente conectada con una nueva intuición de la vida, hasta que se convierta en una manera nueva de experiencia y de ver la realidad... (Gramsci, 2007, p. 2,192)

Para Gramsci es crucial el problema de la organización de la cultura en su teoría de la revolución hasta el punto que se convierte en un elemento primario en la lucha de la clase obrera para lograr su hege- monía. Sin duda, el problema del arte, de la crítica literaria y del papel del artista no pueden aislarse de su visión general de la construcción de una estrategia socialista para forjar una nueva hegemonía cultural. 


\section{La unidad dialéctica de forma y contenido en el arte}

La estética marxista desde sus comienzos ha insistido en la unidad de forma y contenido en el arte, o en otras palabras, de su interdependencia. También ha enfatizado la prioridad del contenido sobre la forma. Cualquier forma de arte que pertenezca a un elevado nivel de lo real por necesidad encuentra una elevada forma de expresión. En el caso ruso (después de la revolución), el enfoque estético dominante eliminó del marxismo una importante adquisición hegeliana: la identificación de lo bello con lo real. A esto le siguió un desprecio total por la "forma" en el arte durante el período estalinista, y a una feroz oposición al "formalismo" que prevaleció entre los años 1921 y 1925. El formalismo reduce el arte a nada más que a su forma y estilo, y permanece indiferente a su "contenido" (Arvon, 1973, p. 43).

El idealismo hegeliano también insiste en la unidad de contenido y forma para determinar qué es lo bello y lo real en el arte. Dicha unidad, sin embargo, es postulada a priori por el artista en el preciso momento de su creación. En el mismo sentido, Croce (2004, p. 31) hace del principio de la identidad de forma y contenido, la base de su teoría estética en oposición a la escuela formalista. En el acto estético, forma y contenido no pueden separarse, ningún contenido puede imaginarse sin la forma, igualmente ninguna forma sin contenido. La intuición (el contenido) y la expresión (la forma) no pueden separarse. Este dualismo, para Croce, se resuelve especulativamente en una síntesis a priori en el espíritu del artista y no en la dinámica de la historia. Gramsci acepta el principio de la identidad de forma y contenido, pero lo transpone del sujeto a la historia y le da un nuevo significado. Para Croce, el contenido es intuición y la forma es la expresión; para Gramsci, contenido es "la masa de sentimientos y actitudes hacia la vida que circula en la obra de arte" (Gramsci, 2007, p. 1,793). Comprendida en este sentido, el contenido no puede separarse de la forma (expresión). Por lo tanto, en el arte el panorama del artista en la vida no puede aislarse de la manera en la cual expresa su creación. El postulado de Croce de la unidad de contenido y forma buscaba defender la idea de la independencia completa del arte de la filosofía y la ciencia y la superioridad del conocimiento intuitivo sobre el conceptual. Por el contrario, Gramsci siente la necesidad de insertar el arte en la dinámica del proceso histórico y conectarlo a una dialéctica concreta. Para hacer esto, Stipcevic explica, Gramsci recurre a una operación intelectual también derivada de Croce: "Identidad de términos no significa identidad de conceptos" (Gramsci, 2007, p. 1,410). Así, Gramsci 
concluye que es legítimo distinguir (en su unidad) contenido y forma,

y reafirmar la prioridad de uno sobre el otro.

Para establecer el principio de que en una obra de arte uno tiene que investigar solamente el carácter estético, uno no excluye la búsqueda por esos sentimientos y actitudes hacia la vida que circula en la obra de arte misma (...) Lo que se excluye es que una obra es bella por su contenido moral y político y no por su forma. (Gramsci, 2007, p. 1,793)

Interviniendo en la polémica entre aquellos que insisten en el contenido y quienes insisten en la forma en el arte, Gramsci -como Croce antes que él- rechaza el dualismo. Mientras que Croce enfatiza en la forma, Gramsci lo hace en el contenido. Un pasaje de gran significación: "contenido y forma a la par del significado 'estético', tienen también un significado "histórico" (Gramsci, 2007, p.1,738). El arte es en definitiva forma condicionada por el contenido, en sí mismo históricamente determinado. Continuando con la defensa del principio de que ninguna prioridad de contenido sobre la forma está dada en el acto estético, uno solamente puede insistir sobre dicha prioridad históricamente, cuando existe un conflicto para una cultura nueva. De este modo, Gramsci, de un concepto de identidad absoluta de forma y contenido, arriba a uno de identidad relativa. Este nuevo sentido se necesita en la noción de la historicidad del arte y en la lucha revolucionaria para la creación de una cultura nueva. Este planteo teórico puede argumentarse que es la contribución de Gramsci a la estética marxista. Obviamente, estas ideas emergen en Gramsci como producto de su diálogo con Croce y de su crítica intelectual.

\section{El carácter de la crítica en la estética marxista}

De nuevo, una comparación con Croce resulta útil. Comenzando con la premisa de que la obra de arte es completa y perfecta en el sujeto, Croce concluye que la crítica estética no tiene soporte en el contenido del arte sino sólo en su forma. De lo que se deduce que la crítica estética es formalista, técnica e imparcial. En la literatura, por ejemplo, la crítica persigue discriminar que es poesía y que no lo es. Al respecto Stipcevic comenta que la crítica para Croce, no es una crítica a los valores estéticos, sino al pronunciamiento de la existencia del fenómeno artístico. Esto equivale a decir que el valor de una obra de arte está en su existencia. La crítica estética discrimina entre el fenómeno artístico y 
el que no lo es desde el punto de vista de la "forma" (Stipcevic, 1968, pp. 40-41). Para Gramsci, existen dos series de hechos: "uno de carácter estético, o arte puro, el otro de política cultural (es decir sólo político)". Por lo tanto, la crítica es política y estética. Gramsci nunca define el objeto y los criterios de la primera, sino que se enfoca en la segunda. $Y$ lo que es importante hacer notar de su enfoque es que fusiona las dos en una síntesis superior: la crítica cultural. La crítica estética es finalmente política.

El tipo de crítica literaria propia de la filosofía de la praxis (...) debe fusionar la lucha por una cultura nueva, es decir por un nuevo humanismo, la crítica de las costumbres, sentimientos y concepciones del mundo, con la crítica estética, o solamente artística con un fervor pasional, incluso en la forma de sarcasmo. (Gramsci, 2007, p. 2,188)

El mejor ejemplo de este Francesco de Sanctis. Como Gramsci tipo de crítica lo proporciona lo indica:

La crítica de Sanctis es militante, no "claramente" estética; es la crítica de un período de estrategias culturales, de contrastes entre concepciones antagónicas del mundo. El análisis del contenido, la crítica de la "estructura" de las obras, es decir la coherencia lógica e histórica-práctica de los sentimientos representados artísticamente, están ligados a esta lucha cultural. (Gramsci, 2007, p. 2,188)

Para estar seguros, tanto Croce como De Sanctis están comprometidos a una ideología, pero éste último ofrece un tipo de crítica literaria muy superior a la de Croce, precisamente porque no se limita a la crítica de la forma pura, sino al contenido y a la forma juntos. En este caso, reconocemos un enfoque marxista muy conocido y quien mejor lo articula es Lukács
(Petronio,1971). Un período histórico determinado está lleno de contradicciones. En éste, una actividad y una praxis fundamental predominan y representan un momento progresivo en el desarrollo de la historia. Este momento puede representarse como progresivo, reaccionario, anacrónico en sus rasgos generales. Esto último es típicamente marxista. Gramsci (2007) señala:

Hay algunos que representan esta actividad predominante, este 'punto histórico' progresivo; pero ¿cómo uno puede juzgar 
otros que representan otras actividades o elementos en la obra de arte? ¿Y estos son también "representativos"? ¿Y otros que representan elementos "reaccionarios" y anacrónicos, son también los que simbolizan ese aspecto de la obra de arte? ¿Debe decirse que sólo esos artistas que aprovechan todas las fuerzas y elementos en su conflicto esencial, es decir, quienes aprovechan las contradicciones de la totalidad socio-histórica, son verdaderamente artistas representativos?

Es por esto que Marx y Engels admiraban a Balzac, y es por la misma razón que Gramsci admira a De Sanctis. La crítica estética es eminentemente histórica en la medida que brota de la relación del artista con la historia que está desarrollándose. Como lo indica Scalia, Gramsci insiste en que el fenómeno artístico tiene que estar cimentado dentro de un mundo socio-cultural, pero que la crítica estética tiene que ser distinta de éste. En una carta desde la prisión, Gramsci (1975) dice:
Tal vez he hecho una distinción entre un disfrute estético y un juicio positivo de valor por la belleza artística, i.e., entre un entusiasmo por una obra de arte en sí misma y un entusiasmo moral, por lo que quiero decir un deseo de participar en el mundo ideológico del artista - una distinción que me parece justa y necesaria. Puedo admirar La Guerra y la Paz de Tolstoi desde un punto de vista estético sin estar de acuerdo con los contenidos ideológicos del libro. Si ambos factores coinciden, Tolstoi podría ser mi vade mecum, mi livre de chevet. (p. 245)

Con respecto a la orientación general de la crítica, Gramsci distingue una "crítica tendenciosa" de una "crítica de tendencias". Como Guiducci apropiadamente lo observa, Gramsci propone esta última. Las características propias de dichas críticas son: la capacidad de comprender y caracterizar todas las fuerzas en conflicto entre ellas y estimular el desarrollo de las más progresistas (Guiducci, 1975, p. 375). La "actividad crítica normal", Gramsci indica, "es principalmente de carácter 'cultural'y es una crítica 'tendencias', de otra manera podría ser una masacre continua" (Gramsci, 2007, p. 2,231). Si la crítica es limitada a la forma como en el caso de Croce, entonces podría ser una actividad negativa o crítica aburrida. La crítica positiva en su lugar está dirigida a ambas, de este modo es una crítica 
social y cultural. No es una crítica militante o neutral lo que Gramsci tiene en mente sino una crítica que sea eminentemente histórica (Scalia, 1968, p. 351).

\section{La crítica estética y la crítica política}

Gramsci (2007) distingue la embargo, estos dos tipos de crítica crítica estética de la política. La no son completamente indepenprimera se sostiene en la forma, dientes.

la segunda en el contenido. Sin

Dos escritores pueden representar (expresar) el mismo momento socio-histórico, pero uno puede ser artista, el otro un hipócrita. Para limitarnos a describir que representan o expresan socialmente, es decir, sintetizando más o menos las características de cierto período socio-histórico, significa tocar apenas el problema estético. Todo esto puede ser útil y necesario, y ciertamente lo es, pero en otra esfera, de la crítica política, la crítica a las costumbres, la lucha por destruir y trascender ciertas corrientes de sentimientos y creencias, ciertas actitudes hacia la vida y el mundo (...)

Pero ¿cómo decidir quién es un artista verdadero? "Este es el quid de la polémica: $X$ "quiere" expresar artificialmente un cierto contenido, pero no produce un trabajo artístico (...) El crítico político asegura que $X$ no es un artista, sino un "oportunista político" (Gramsci, 2007, pp. 1,793-4). El crítico político no interviene para expresar un juicio de valor en la obra de arte, sino para descreditar sus pretensiones políticas. Esto no demanda una conver- gencia y consonancia con las metas políticas y artísticas. Esto expresa un juicio sobre la sinceridad de las verdades artísticas, no de la obra de arte per se, sino en la materia que crea. Gramsci se opone a la politización completa del arte, así como a su completa autonomía. Dada la dependencia del arte de la cultura y su importancia práctica en la organización de la cultura, las tensiones entre el arte y la política son inevitables.

La presión del político por el arte de su tiempo que exprese un mundo cultural específico es una actividad política y no crítica artística: si el mundo cultural por el que uno lucha es un hecho viviente y necesario, su expansión será inevitable, y producirá sus propios artistas. Pero, si a pesar de la presión, esta 
inevitabilidad no es percibida, esto significa que fue una cuestión de un mundo ficticio y artificial (...). (Gramsci, 2007, pp. 1,793-4)

La crítica política no tiene como objetivo educar autoritariamente al artista, sino de clarificar su papel respectivo en el proceso de reconstrucción cultural de la sociedad. El político y el artista son conscientes de sus limitaciones, pero como el arte y la praxis política están cimentadas en la misma realidad histórica, la intervención de ésta última en materia de estética puede justifi- carse sólo desde un punto de vista ético. El político tiende a desenmascarar este o aquel artista, de su no arraigo al desarrollo objetivo y dirección de la historia. Gramsci (2007) intenta clarificar más adelante las funciones de las dos en un texto donde la relación entre la literatura y la política es examinada con más detenimiento.

Hasta donde la relación entre literatura y política compete, uno debe tomar en cuenta este criterio: el hombre de letras debe tener necesariamente perspectivas menos precisas y definitivas que un político, debería ser, por así decirlo, menos "partisano", pero en una forma "contradictoria". Para el político cualquier a priori imagen "fijada" es reaccionaria: él concibe todo el movimiento en su devenir. El artista en cambio tendrá imágenes "fijadas" puestas en su forma definitiva. El político imagina al hombre tal como es, y al mismo tiempo, como debería ser, para obtener un cierto fin; su tarea es precisamente esa, de presionar a los hombres a moverse (...) Así, desde un punto de vista político, el político nunca estará satisfecho con el artista, y no puede estarlo: siempre lo encontrará detrás de los tiempos, siempre anacrónico, siempre aventajado por el movimiento real. (p. 1820)

Al leer este texto de Gramsci, no queda ninguna duda de su compromiso ideológico con la "crítica política”, pero, considerando el hecho que fue un intelectual militante revolucionario, debe dársele crédito por haber reconocido el valor de la crítica estética y su relativa independencia de la crítica política. Al hacerlo, Gramsci evita los peligros de la politización del arte, y su sumisión a la política del partido como sucedió en la era estalinista y en las experiencias del "socialismo real". Muchos pueden estar en desacuerdo con Gramsci en este punto, pero el desacuerdo, sin embargo, sería materia de una 
decisión ética. Gramsci escoge vincular el arte a la sociedad y a la cultura de manera ética e ideológica y no teóricamente. Como Guiducci (1976) lo comenta, la estética gramsciana no es abierta ni flexible, y no lo puede ser, en la medida que el contenido de la producción artística se lleve a cabo en la historia (pp. 378-379).

\title{
5. El carácter popular de las formas de arte
}

El interés de Gramsci en la estética, como se ha mostrado, no es filosófico ni teórico, sino sociológico. En lugar de preguntarse qué es lo bello en el arte, el revolucionario italiano está interesado en conocer por qué un cierto tipo de arte es disfrutado por el público. Tomando el ejemplo de la literatura, Gramsci señala que su popularidad no está determinada por su "belleza" sino por un contenido específico que es capaz de cautivar a las masas.

\begin{abstract}
La belleza no es suficiente. Lo que se necesita es un cierto contenido intelectual y moral que es la elaboración y la expresión completa de las profundas aspiraciones de un cierto público, este es el pueblo-nación en una cierta fase de su desarrollo histórico. (Gramsci, 2007, p. 2,113)
\end{abstract}

Cuanto más la literatura se arraiga a la cultura y a los "sentimientos nacionales", en un movimiento continuo, más popular es su carácter. Gramsci poseía un juicio negativo de la literatura italiana, en su contenido y forma está separada de las masas. Esta es la consecuencia de la separación de los intelectuales de las masas. No existe una concepción común del mundo: "Los sentimientos populares no son experimentados por los escritores como propios" (Gramsci, 2007, p. 2,114). Lo que hace el arte y la literatura popular es el arraigo de su contenido a los sentimientos y las experiencias de las masas.

El contacto inmediato entre el lector y el escritor se lleva a cabo cuando el lector se da cuenta de la unidad de contenido y forma, la premisa de la cual es la unidad entre el mundo poético y sentimental. De otra manera, el lector tiene que traducir el 'lenguaje' del contenido a su propio lenguaje. (Gramsci, 2007, p. 732)

Algunos han atribuido a Gramsci ideas populistas. Populismo es una forma de neo-realismo, de acuerdo con el cual la gente se convierte 
en sujeto y objeto de la producción artística. De hecho, un arte y una literatura populista conducirían al sentido común. En torno a esta visión de mundo, Gramsci mantiene una posición crítica dada su naturaleza fragmentada y contradictoria, y lo importante que resulta la transformación del sentido común subalterno en una concepción superior de la realidad. Las formas artísticas para Gramsci deben ayudar el proceso de elevación cultural de las masas. La noción de "popular" está - para Gramsci- siempre asociada con lo "nacional", y está en cierta medida opuesta al folklore y al sentido común. El folklore es una concepción del mundo particularista, provincial y anacrónica, típica de un grupo social carente de características universales. La noción de lo "popular-nacional" se refiere a una concepción del mundo más avanzada, moderna y cosmopolita (Gramsci, 2007, p. 1,660). Ciertamente, algunas veces Gramsci parece defender una forma populista de literatura.

La premisa de una literatura nueva no puede ser sino histórica, política, popular. Debe tender a desarrollar lo existente, polémicamente o de otra manera; lo importante es que se encuentre arraigado en el humus de la cultura popular, como ésta lo sea, con sus gustos, sus tendencias, etc., con su mundo moral e intelectual, ya sea atrasado o convencional. (Gramsci, 2007, p. 1,822)

Aquí encontramos un ejemplo que va más allá de textos particulares y que capta el sentido general del pensamiento de Gramsci. La actitud de la gente hacia el arte y la atracción ejercida por las formas artísticas en las masas siempre tiene que ser explicada en términos de razones culturales y prácticas. Las masas están interesadas en el contenido de las obras de arte más que en su forma. Esto explica por qué las masas son atraídas por las historias de detectives y de aventuras, las novelas de suspenso y románticas. De lo que se desprende la necesidad que tiene la estética marxista de enfocarse en el conte- nido para elevar los gustos literarios y artísticos de las masas. Como lo expresa Stipcevic en sus conclusiones, una "literatura popular" que actúa en la conciencia y el conocimiento, y que introduce nuevos conceptos revolucionarios en el sentido común de las masas, es para Gramsci de una gran importancia hegemónica (Stipcevic, 1968, p. 70).

Algunas observaciones generales pueden hacerse a manera de conclusión en torno a las temáticas comentadas. Gramsci analiza sólo algunos aspectos socio-históricos del fenómeno estético. Su intención es cimentar la creación artística en 
la realidad dinámica y dialéctica de la historia. El arte, en primer lugar, debe estar ligado a la historia humana y a relaciones sociales concretas. En este sentido, es dependiente -incluso en un grado limitado- de la praxis política. Segundo, el arte debe ser dotado con una cierta autonomía en relación a la política. El arte nace espontáneamente y no puede ser impuesto desde arriba o desde fuera. Tercero, el arte debe facilitar el libre desarrollo de las fuerzas progresistas revolucionarias. Gramsci enfoca el sujeto de la creación artística desde una perspectiva política. El arte es social e histórico, y como todas las otras actividades intelectuales, se esparce en sí mismo y se vuelve un encanto a los seres humanos debido a los elementos prácticos y externos. Lo que es de interés en el arte son siempre los elementos externos que pertenecen a la cultura, la cual cambia de acuerdo a las épocas, al clima cultural e incluso a los estados de ánimo personales. Gramsci comenta que la "métrica bárbara" en los poemas de Carducci se convirtió en una innovación artística atractiva pero sólo para un círculo estrecho de escritores y de aquellos que aspiraban serlo. Gramsci llega a la afirmación de la necesidad de una participación activa y consciente del artista en el proceso de su realización. Por supuesto que esto no significa la politización del arte y la sumisión a la política de un partido u organización. Cuando un grupo social hace su aparición en la historia y aspira a ser hegemónico, de su seno surgirán espontáneamente artistas para expresar en forma creativa las exigencias de la nueva totalidad. El arte es revolucionario, entonces, cuando brota del interior de un ser humano renovado (Stipcevic, 1968, p. 70). Cuando Gramsci evoca la necesidad de representar el arte "popular", y realiza una investigación acerca de lo que constituye el "interés" para las masas, está en efecto subordinando el papel del artista a la conciencia de las necesidades de las masas. Los sentimientos del artista deben armonizar los elementos subjetivos y objetivos. Lenin (2010) y Gramsci están de acuerdo en condenar el arte por el arte, y hacen de las masas actores activos y conscientes en la producción del arte.

El marxismo de Gramsci es profundamente humanista. En ese sentido, examina tanto las intenciones del artista como sus resultados. Habla de un conformismo racional en el arte. El conformismo es un esfuerzo concertado de alcanzar un fin práctico espontáneamente y no por medio de la coerción. La conformidad racional no niega la individualidad, originalidad y creatividad. Existe una "conformidad racional", por ejemplo, en la arquitectura y esto es -expresa Gramsci- "la expresión de lo Bello de acuerdo al gusto de un cierto período", en otras palabras, el logro 
racional de una meta está basado en un determinado gusto y conocimiento técnico (Gramsci, 2007, p. 1,656). Si por originalidad uno quiere decir hacer lo opuesto de lo que otros hacen, en ese caso tenemos una conformidad mecánica, artificial, impuesta externamente por grupos reducidos. Una estructura arquitectónica es la manifestación externa del arte, la posibilidad dada al público de participar en la creación de lo bello. Es una interpretación de lo que es práctico y útil, en palabras de Gramsci. ¿Es posible "planear" el arte y al "artista" sin eliminar su originalidad e individualidad? Gramsci responde paradójicamente: ¡sí! Conformidad racional, conformidad artística e individualismo pueden ser dialécticamente fusionados. Originalidad individual implica, en su más alto grado, el máximo de socialidad e historicidad; cuanto más el individuo se arraiga al desarrollo objetivo de la historia, más original lo es. Mientras la espontaneidad per se conduce al arte por el arte, la espontaneidad disciplinada conduce a la creación artística más original.

\section{Referencias}

- Anderson, P. (1976). The Antinomies of Antonio Gramsci. New Left Review 1, (100). Pp.5-78.

- Arvon, H. (1973). Marxist Aesthetics. Ithaca, USA: Cornell University Press.

- Croce. B. (2004). Aesthetics as Science of Expression and General Linguistics. Kessinger, USA: Pub. Co.

- Gramsci, A. (1975). Letters from Prison. Nueva York, USA: Lynne Lawner.

. (2007). Prison Notebooks 3. Nueva York: Columbia University Press. . (2008). Gramsci en la cultura contemporánea Vol. 2. Roma, Italia: Instituto Gramsci.

- Guiducci, R. (1976). Sulla fine della clase degli intellectual. Torino, Italia: Socialismo e Veritá.

- Jay, M. (1973). The Dialectical Imagination: A History of the Frankfurt School and the Institute of Social Research. Boston, USA: Little Brown.

- Lenin, VI. (2010). Lenin on Literature and Art. Lavegne TN, USA: Wilside Press.

- Marx, K. (1972). Introduction to the Critique of Political Economy. En B. Lang, y F. Williams (Eds.). Marxism and Art. Nueva York, USA: Dave Mckay. 
- Morton, A. D. (2003). Historicizing Gramsci: Situating Ideas and beyond their context. Review of International Political Economy 10, (1). Pp. 118-46.

- Petronio, G. (1971). Gramsci e la critica letteraria. Studi Gramsciani. Roma, Italia: s.e.

- Scalia, G. (1968). Metodologia e sociología della letteratura in Gramsci. En A. Caraccciolo, y G. Scalia. La Citta Futura. Milano, Italia: Feltrinelli.

- Stipcevic, N. (1968). Gramsci e i problema letterari. Milano, Italia: Mursia. 